\title{
What Should We Agree on about the Repugnant Conclusion?
}

\author{
Stéphane Zuber (D), Nikhil Venkatesh (D), Torbjörn Tännsjö (D), Christian Tarsney, \\ H. Orri Stefánsson (D), Katie Steele, Dean Spears* (D), Jeff Sebo, Marcus Pivato (D), \\ Toby Ord (D), Yew-Kwang Ng, Michal Masny (D), William MacAskill, Nicholas Lawson, \\ Kevin Kuruc, Michelle Hutchinson (D), Johan E. Gustafsson (D), Hilary Greaves, Lisa Forsberg, \\ Marc Fleurbaey, Diane Coffey, Susumu Cato (D), Clinton Castro, Tim Campbell, \\ Mark Budolfson, John Broome (D), Alexander Berger, Nick Beckstead and Geir B. Asheim (iC) \\ Paris School of Economics, CNRS, University College London, Stockholm University, University of Oxford, \\ Stockholm University, SCAS (Uppsala), and Institute for Futures Studies (Stockholm), Australian National \\ University, University of Texas at Austin, ISI-Delhi, IZA (Bonn), Institute for Futures Studies (Stockholm), \\ and r.i.c.e (Lucknow), New York University, CY Cergy Paris Université, University of Oxford, Peking \\ University and Monash University, Princeton University, University of Oxford, Université du Québec à \\ Montréal, University of Oklahoma, 80,000 Hours (Oxford), University of York, University of Gothenburg, \\ and Institute for Futures Studies (Stockholm), University of Oxford, University of Oxford, Paris School of \\ Economics, University of Texas at Austin, University of Tokyo, Florida International University, Institute \\ for Futures Studies, Rutgers University, University of Oxford and Australian National University, \\ Open Philanthropy (San Francisco), Open Philanthropy (San Francisco) and University of Oslo \\ *Corresponding author: dspears@utexas.edu.
}

The Repugnant Conclusion is an implication of some approaches to population ethics. It states, in Derek Parfit's original formulation,

For any possible population of at least ten billion people, all with a very high quality of life, there must be some much larger imaginable population whose existence, if other things are equal, would be better, even though its members have lives that are barely worth living. (Parfit 1984: 388)

This conclusion has been the subject of several formal proofs of incompatibility in the literature (Ng 1989; Arrhenius 2000, forthcoming) and has been an enduring focus of population ethics.

The Repugnant Conclusion served an important purpose in catalyzing and inspiring the pioneering stage of population ethics research. We believe, however, that the Repugnant Conclusion now receives too much focus. Avoiding the Repugnant Conclusion should no longer be the central goal driving population ethics research, despite its importance to the fundamental accomplishments of the existing literature.

\section{What we agree on}

We agree on the following:

1. The fact that an approach to population ethics (an axiology or a social ordering) entails the Repugnant Conclusion is not sufficient to conclude that the approach 
is inadequate. Equivalently, avoiding the Repugnant Conclusion is not a necessary condition for a minimally adequate candidate axiology, social ordering, or approach to population ethics.

2. The fact that the Repugnant Conclusion is implied by many plausible principles of axiology and social welfare is not a reason to doubt the existence or coherence of ethics and value theory (although we do not rule out that there may be other reasons for moral skepticism).

3. Further properties of axiologies or social orderings - beyond their avoidance of the Repugnant Conclusion - are important, should be given importance and may prove decisive.

To clarify what we do not claim in our agreements 1,2 , and 3:

- We do not here endorse or oppose the Repugnant Conclusion, nor total utilitarianism, nor indeed any specific approach.

- We do not here support or oppose any population policy, nor make any claim about any empirical consequence of population growth for sustainability or other outcomes.

- Our shared claim that avoiding the Repugnant Conclusion is not necessary does not take a position on whether avoiding the Repugnant Conclusion is desirable in evaluating a candidate axiology, social ordering, or approach to population ethics.

- We do not claim or deny that the Repugnant Conclusion is meaningful or welldefined, nor that a life worth living is well-defined (see Broome 2004 and more detail in the next section).

\section{Brief summaries of alternative paths to the claims we agree on}

Among us, we disagree about some of the reasons for, and implications of, our agreements in Section 1. In the rest of this statement, we summarize the alternative arguments by which various authors reach our shared conclusions. About what follows, we disagree with one another. Each of us endorses at least one of the following arguments and some of us reject one or more of these arguments.

The intuition that the Repugnant Conclusion is repugnant may be unreliable. Rejecting the Repugnant Conclusion depends crucially on our intuitions. These intuitions can be unreliable for a number of reasons. (i) The Repugnant Conclusion depends crucially on intuitions about cases with very large numbers of people. The size of such very large numbers is hard to grasp on an intuitive level (Broome 2004; Huemer 2008; Gustafsson, forthcoming). (ii) It may be hard to avoid implicitly including ourselves in the populations we imagine. If so, we may have an egoistic bias in favor of populations with a high quality of life (Tännsjö 2002; Huemer 2008). (iii) We are also bad at compounding small numbers. We may therefore fail to see how lots of lives with a small but positive value could add up to something very valuable (Huemer 2008). (iv) Finally, we may wrongly take lives that are "barely worth living" to be bad rather than good (Huemer 2008). Or we may be misled by standard examples of lives "barely worth living" in the literature: lives in such examples may appear to be or in fact be not worth living or even worth not living (Hutchinson 2014); may be not much worse than our lives; or, alternatively, may be well worth living.

The impossibility theorems in population ethics can be read as strong arguments for the Repugnant Conclusion. If so, the aggregation of many worthwhile lives may indeed 
be better than a moderate number of very good lives (Tännsjö 2002, 2020; Adler 2008; Huemer 2008). It is not unusual for social evaluations in other settings to weigh options in this way; for example, there are well-studied unintuitive consequences of aggregation in same-number cases (Cowen 1996). Moreover, any repugnance in Parfit's initial illustration of the Repugnant Conclusion is also found in addition cases, where lives are added to an unaffected sub-population (such as the set of past people); therefore, such repugnance is entailed even by average utilitarianism and other views that are commonly understood to avoid the Repugnant Conclusion (Anglin 1977; Budolfson and Spears 2018; Spears and Budolfson 2021).

An approach that entails the Repugnant Conclusion need not entail any repugnant recommendations in practice. The Repugnant Conclusion assumes that the size of potential populations is unbounded. It may be unrealistic that the much larger population in the Repugnant Conclusion could ever exist. Indeed, approaches that imply the Repugnant Conclusion may turn out to agree with approaches that avoid the Repugnant Conclusion in all feasible or in all relevant decision-making contexts (Arrhenius et al. 2020). In addition, the reasons why we accept an approach may be the result of a reflective equilibrium that entails considering the implications of the approach in specific contexts. In this reflective equilibrium, consequences for practically relevant cases may be more important than principles for infeasible cases (Fleurbaey and Tungodden 2010). For example, one could argue for critical-level generalized utilitarianism if separability appears plausible but mere addition appears implausible in practical, bounded cases - without making any reference to the Repugnant Conclusion.

If there is no logically prior concept of a life worth living, then the Repugnant Conclusion may be ill-defined. Although the Repugnant Conclusion necessarily uses a concept of a life barely worth living, it might not be legitimate to use this concept for at least two reasons. (i) It may not be clear what we mean by "a life worth living" and whether it exists outside of a specific context (Broome 1993, 2004). (ii) One may further argue that whether additional lives make a population better depends on the full social ordering. For either of these reasons, we might be unable to evaluate the Repugnant Conclusion. If so, the Repugnant Conclusion and any principle relying on a logically prior value for the critical level would not be a useful guide to choosing among approaches.

If one accepts a person-affecting approach, then the large population may be at least as good (or as permissible) as the small population in cases where the persons in each are different. If a life barely worth living is the best accessible life for each person in the large population then a person-affecting approach may see no reason to prefer the smaller population (Parfit 1984: 395; Roberts 2015). Of course, such a specific large population may be unlikely ever to be a practically available option, but the Repugnant Conclusion requires only an "imaginable" case. So, with such a person-affecting approach, entailing the Repugnant Conclusion in this way (and possibly others) would not indicate inadequacy.

\section{Conclusion}

Late in his career, Parfit revised his prior arguments regarding the Repugnant Conclusion, calling his prior reasoning a "mistake" on the grounds that "We cannot justifiably reject strong arguments merely by claiming that their conclusions are implausible" (Parfit 
2017: 154). Parfit might never have agreed with our claims 1, 2, and 3, but we agree with him that conclusions that appear implausible are sometimes true.

Ethical arguments are widely used in public debate, everyday decision-making, and policy-making. For example, ethical arguments against social inequality and discrimination are common - although not universal, not always successful, and not always correct. Many public decisions affect the world's future population. Population ethics is therefore an essential foundation for making these decisions properly. It is not simply an academic exercise, and we should not let it be governed by undue attention to one consideration. Perhaps someday the correct approach to axiology, social welfare, or population ethics will be agreed upon among experts. If so, we do not know whether the approach used will entail the Repugnant Conclusion. We should keep our minds open.

Acknowledgements. This research is supported by a Dr. Cécile DeWitt-Morette France-UT Endowed Excellence Grant; by grants K01HD098313 and P2CHD042849 awarded to the Population Research Center at UT-Austin by the NICHD (the content is solely the responsibility of the authors and does not necessarily represent the official views of the National Institutes of Health); and by the Agence nationale de la recherche through the Investissements d'Avenir program (ANR-17-EURE-01).

\section{References}

Adler, Matthew. 2008. Future Generations: A Prioritarian View, George Washington Law Review, 77.5-6: 1478-520.

Anglin, Bill. 1977. The Repugnant Conclusion, Canadian Journal of Philosophy, 7.4: 745-54.

Arrhenius, Gustaf. 2000. An Impossibility Theorem for Welfarist Axiologies, Economics and Philosophy, 16.2: $247-66$.

Arrhenius, Gustaf. Forthcoming. Population Ethics: The Challenge of Future Generations (Oxford: Oxford University Press).

Arrhenius, Gustaf, Mark Budolfson, and Dean Spears. 2020. Does Climate Change Policy Depend Importantly on Population Ethics? Deflationary Responses to the Challenges of Population Ethics for Public Policy, in Philosophy and Climate Change, ed. by Budolfson, Mark, Tristram McPherson, and David Plunkett (Oxford: Oxford University Press), pp. 111-36.

Broome, John. 1993. Goodness Is Reducible to Betterness: The Evil of Death Is the Value of Life, in The Good and the Economical: Ethical Choices in Economics and Management, Ethical Economy, ed. by Peter Koslowski and Yuichi Shionoya (Berlin: Springer), pp. 70-84.

Broome, John. 2004. Weighing Lives (Oxford: Oxford University Press).

Budolfson, Mark and Dean Spears. 2018. Why the Repugnant Conclusion Is Inescapable. Princeton University Climate Futures Initiative working paper.

Cowen, Tyler. 1996. What Do We Learn from the Repugnant Conclusion?, Ethics, 106.4: 754-75.

Fleurbaey, Marc and Bertil Tungodden. 2010. The Tyranny of Non-Aggregation versus the Tyranny of Aggregation in Social Choices: A Real Dilemma, Economic Theory, 44.3: 399-414.

Gustafsson, Johan E. Forthcoming. Our Intuitive Grasp of the Repugnant Conclusion, in The Oxford Handbook of Population Ethics (New York: Oxford University Press).

Huemer, Michael. 2008. In Defence of Repugnance, Mind 117.468: 899-933.

Hutchinson, Michelle. 2014. The Ethics of Extending and Creating Life (unpublished doctoral thesis, University of Oxford).

Ng, Yew-Kwang. 1989. What Should We Do about Future Generations? Impossibility of Parfit's Theory X, Economics and Philosophy, 5.2: 135-253.

Parfit, Derek. 1984. Reasons and Persons (Oxford: Clarendon Press)

Parfit, Derek. 2017. Future People, the Non-Identity Problem, and Person-Affecting Principles, Philosophy \& Public Affairs, 45.2: 118-57.

Roberts, Melinda. 2015. Population Axiology, in The Oxford Handbook of Value Theory, ed. by Iwao Hirose and Jonas Olson (New York: Oxford University Press), pp. 399-423. 
Spears, Dean and Mark Budolfson. 2021. Repugnant Conclusions, Social Choice and Welfare, https:// doi.org/10.1007/s00355-021-01321-2.

Tännsjö, Torbjörn. 2002. Why We Ought to Accept the Repugnant Conclusion, Utilitas, 14.3: 339-59.

Tännsjö, Torbjörn. 2020. Why Derek Parfit Had Reasons to Accept the Repugnant Conclusion, Utilitas 32.4: 387-97.

Cite this article: Zuber S et al (2021). What Should We Agree on about the Repugnant Conclusion? Utilitas 33, 379-383. https://doi.org/10.1017/S095382082100011X 